\title{
A desconstrução de discursos discriminatórios de sexualidade e gênero: apresentando diagnósticos e problematizações pertinentes à Educação
}

The deconstruction of discriminatory discourses of sexuality and gender: presenting diagnoses and problematizations that are relevant to Education

\author{
André Luís Carolli
}

Maria José de Jesus Alves Cordeiro²

\begin{abstract}
'Universidade Estadual Paulista (Unesp), Faculdade de Ciências, Programa de Pós-graduação em Educação para a Ciência, Bauru, SP, Brasil. Autor Correspondente: andre.carolli@unesp.br

${ }^{2}$ Universidade Estadual de Mato Grosso do Sul (UEMS), Campus Paranaíba, MS, Brasil.
\end{abstract}

Resumo: A partir das ideias da Desconstrução, de Derrida, desenvolveu-se a desmontagem de discursos discriminatórios da Sexualidade e Gênero, altamente danosos socialmente, a partir de entrevistas com educandos, especialmente, mediante a Arqueologia do Saber e a Genealogia do Poder, segundo Foucault. O objetivo foi apurar a existência de falhas de fundamentação científica, incoerências e contradições nos discursos discriminatórios. Apurou-se forte presença do Logocentrismo embasando discriminações. Nesse âmbito, a ausência da Lógica Formal, associada à falta de conhecimento científico, leva $55,2 \%$ de discentes a aderir acriticamente às proposições baseadas em leituras bíblicas descontextualizadas que excluem a hermenêutica. Tais leituras errôneas alimentam formações discursivas discriminatórias, figurando como permanente possibilidade de retrocessos civilizatórios. A Desconstrução se apresentou como caminho viável para o desenvolvimento de estratégias pedagógicas para combate a preconceitos, mediante a educação em todos os níveis e modalidades de ensino.

Palavras-chave: Educação e sexualidade; Conhecimento científico; Lógica formal; Discurso discriminatório; Ciência e religião.

Abstract: Based on Derrida's ideas on Deconstruction, there was the dismantling of discriminatory discourses of Sexuality and Gender - which are highly damaging socially - developed through interviews with students, especially influenced by the Archeology of Knowledge and the Genealogy of Power, according to Foucault. The objective was to ascertain the existence of flaws in scientific reasoning, inconsistencies and contradictions in discriminatory discourses. There is a strong presence of Logocentrism, on the basis of discrimination. In this context, the absence of Formal Logic, associated with the lack of scientific knowledge, leads $55.2 \%$ of students to uncritically adhere to propositions based on decontextualized biblical readings that exclude hermeneutics. Such erroneous readings feed discriminatory discursive formations, figuring as a permanent possibility of civilizing regression. Deconstruction presented itself as a viable path for the development of pedagogical strategies to combat prejudice, through education, at all levels and modes of teaching.

Keywords: Education and sexuality; Scientific knowledge; Formal logic; Discriminatory speech; Science and religion.

Recebido em: 15/12/2020

Aprovado em: 10/09/2021 


\section{Apresentação e justificativa}

Este artigo apresenta resultados de pesquisa contidos na dissertação de Mestrado Acadêmico realizada na Universidade Estadual de Mato Grosso do Sul, intitulada Desconstrução de discursos discriminatórios sobre a diversidade de expressão da sexualidade e da identidade de gênero expressos entre alunos e alunas do ensino médio (CAROLLI, 2017).

Os discursos discriminatórios da Sexualidade e do Gênero têm por base conceitos tradicionais judaico-cristãos que remontam, segundo essa tradição religiosa, à Idade do Bronze ${ }^{1}$, na qual o profeta Moisés teria escrito seus enunciados fundantes, contidos no livro bíblico Levítico, analisados nesta pesquisa; entretanto, pesquisadores como Montalvão (2009) oferecem indicações de que tal texto foi reeditado e finalizado muitos séculos mais tarde por religiosos judeus.

A ideologia associada a esses "discursos" (FOUCAULT, 2008) discriminatórios está apoiada em uma metafísica que Derrida (1973) nominou com o termo "Logocentrismo", constituindo-se em uma tendência ideológica relativa ao Logos $^{2}$, que representa o pensamento resultante do encontro do pensamento grego com o pensamento judaicocristão, nos primeiros séculos da atual era.

Por ser uma metafísica de base religiosa, o Logocentrismo está dissociado da Ciência contemporânea para efeitos de interpretação da realidade. Derrida (1973, p. 98) define o Logocentrismo como "[...] uma metafísica etnocêntrica, em um sentido original e não relativista. Está ligado à história do Ocidente [...]" e ligado à história da religião judaico-cristã; pode ser entendido, segundo o autor, como a tendência do pensamento ocidental de se colocar o Logos como centro de muitos discursos. Na teologia cristã, o conceito filosófico do Logos grego viria, ainda, a ser adaptado no Evangelho de João, no qual o evangelista se refere ao Cristo como o Logos, isto é, a Palavra ou o Verbo encarnado (CAROLLI, 2017), reforçando este discurso.

As discriminações relativas à Sexualidade e Gênero se fazem fortemente presentes em discursos logocêntricos usados, indevidamente, para a justificação e a naturalização ${ }^{3}$ de diferentes práticas violentas, capilarizadas por toda a sociedade, com um espectro que vai desde a preterição de pessoas, passando pela violência verbal, presente no "Discurso de Ódio" (OLIVA, 2014), até a violência física, culminando com assassinatos, conforme descreve denúncia do Grupo Gay da Bahia (2017). Práticas discriminatórias embasadas nessa cultura vão desde a naturalização de tratamentos diferenciados até mesmo ao bullying (BANDEIRA, 2009), abertamente praticado. Estas práticas adentram o universo escolar e passam a fazer parte de um "Currículo Oculto" (SILVA, 1999, p. 78), "[...] constituído por todos aqueles aspectos do ambiente escolar que, sem fazer parte do currículo oficial, explícito, contribuem de forma implícita para aprendizagens sociais relevantes. [...]".

\footnotetext{
'A Idade do Bronze foi um período no qual ocorreu o desenvolvimento da liga metálica de mesmo nome, resultante da mistura de cobre e estanho. O período vai de 3300 a.C., quando este se iniciou no Oriente Médio, e termina em 1200 a. C., com o início da Idade do Ferro.

'Logos: palavra grega que significa palavra ou razão. São reunidos em uma só palavra quatro sentidos principais: (1) linguagem, palavra; (2) pensamento ou razão; (3) norma ou regra; (4) ser ou realidade íntima de alguma coisa.

${ }^{3}$ Quando uma construção social passa a ser considerada um efeito da natureza, ou seja, como presente desde sempre.
} 
Nesse âmbito, a escola não pode fugir à responsabilidade no tratamento desses temas, em virtude de sua própria natureza de "Aparelho ideológico de Estado" (ALTHUSSER, 1985), que tem, no Brasil, duas importantes características definidas constitucionalmente, nos artigos quinto e 206 da Constituição Federal Brasileira, de 1988 (BRASIL, 2012).

O artigo quinto da chamada Constituição Cidadã, democrática, promulgada em 1988, define que deve haver igualdade de tratamento a todas e todos no país. Dessa maneira, "Todos são iguais perante a lei, sem distinção de qualquer natureza, garantindose aos brasileiros e aos estrangeiros residentes no País a inviolabilidade do direito à vida, a liberdade, a igualdade, a segurança e a propriedade [...]". (BRASIL, 2012, grifos nossos). Decorre dessa definição que os sistemas de ensino e seus agentes, tanto na modalidade de ensino público, quanto na modalidade de ensino privado, ambos regulados pelo Estado, também têm o dever de garantir a igualdade entre cidadãs e cidadãos do país.

O artigo 206 da Constituição, por sua vez, define que o ensino escolar deve ser ministrado com princípios de liberdade de pesquisa e concepções pedagógicas, sendo destacado o pluralismo de ideias, diretamente relacionado à diversidade de visões e concepções de vida: "O ensino será ministrado com base nos seguintes princípios: [...]; II - liberdade de aprender, ensinar, pesquisar e divulgar o pensamento, a arte e o saber; III - pluralismo de ideias e de concepções pedagógicas, e coexistência de instituições públicas e privadas de ensino; [...]". (BRASIL, 2012, grifos nossos).

Em função dessas disposições, ensinar sobre o respeito à diversidade, na escola, configura-se não somente como um direito relativo à educação, garantido constitucionalmente, mas também representa um dever de educadoras e educadores de qualquer nível ou modalidade de ensino.

Em face do exposto, a pesquisa que investigou discursos discriminatórios, com o intuito de verificar sua validade científica, nasceu da observação da demanda social pelo tratamento de discriminações relativas à Sexualidade e Gênero, que indicou a necessidade de se tratar esses temas na Educação Formal.

\section{Objetivo}

O objetivo do trabalho foi elencar os principais discursos discriminatórios relativos aos temas Sexualidade e Gênero para então expor os processos formadores desses discursos, denunciando falhas epistemológicas e lógicas, de maneira a contribuir para o exercício de práticas pedagógicas inclusivas, mediante a apresentação de dados com linguagem científica, porém didática, visando ser um trabalho acessível ao maior número de pessoas possível, além de educadoras e educadores.

\section{Metodologia}

Uma pesquisa inicial, sobre o estado da arte, em bancos de dissertações e teses, apontou a possibilidade de contribuição do projeto à educação, quando evidenciou que o uso das ideias da Desconstrução, propostas por Jacques Derrida, como forma de questionar as formações discursivas discriminatórias sobre Gênero e Sexualidade, poderia trazer inovação. 
Desconstrução é um termo emprestado da arquitetura por Derrida que significa desmontagem. Nesta investigação, atuou sobre a interpretação de discursos, fazendo especial uso da Arqueologia do saber (FOUCAULT, 2008) e da Genealogia do poder (FOUCAULT, 2006), apoiadas em diferentes disciplinas e epistemes, como a História, a Linguística, a Filosofia e a Lógica formal. A 'Desconstrução', nesse caso, foi a decomposição dos discursos em seus elementos formadores e a identificação de seus processos constituintes, a fim de expor indefinições e incongruências que indicam a necessidade de reinterpretações, ou seja, de ressignificação.

Trata-se de uma estratégia de análise que visa evidenciar a presença de processos formadores que estão ocultos em textos e, consequentemente, em discursos contidos nesses. Essa estratégia não pode ser chamada de método, pois não há uma fórmula fixa que possa ser aplicada a qualquer situação de análise, lançando-se mão de métodos que sejam pertinentes, à medida que elementos componentes do discurso sejam identificados. Desconstruir, como descrito por Derrida (1973), significa "desmontar" os discursos para identificar processos ocultos, sedimentados, naturalizados, para mergulhar na profundidade da significação, ultrapassando as interpretações que se dão pelo condicionamento cultural trazido pelas construções sociais e históricas: desconstruir é sair da superficialidade para descobrir possíveis fal has de fundamentação e incoerências nas proposições discursivas e, consequentemente, nos discursos, abrindo caminho para que haja a sua ressignificação em função da episteme $e^{4}$ atual.

Constatou-se, durante o exame das teorias pertinentes à desmontagem dos discursos que, especialmente, as ideias sobre "Saber" e "Poder", trazidas por Michel Foucault, apoiadas na Filosofia e em epistemologia científica atualizada, de diferentes disciplinas, seriam adequadas para responder à questão: Os discursos discriminatórios sobre a diversidade de expressão da sexualidade e identidade de gênero se sustentam? (CAROLLI, 2017, p. 12).

Para que houvesse clareza na descrição do desenvolvimento da pesquisa, neste artigo, descrevemos os processos realizados de acordo com as fases de execução do projeto, descritas a seguir.

A primeira fase da execução do projeto foi a realização de uma série de 38 entrevistas com alunas e alunos formandos do Ensino Médio, em uma escola pública de uma cidade projetada, localizada no interior do Estado de São Paulo, com aproximadamente 25 mil habitantes, que apresenta população predominantemente de classe média, concentrada em um perímetro urbano de apenas $5,82 \mathrm{~km}^{2}$ (MIRANDA; GOMES; GUIMARÃES, 2005), resultando em uma densidade populacional aproximada de 4.295 habitantes por $\mathrm{km}^{2}$ (IBGE, 2017), dentro dos limites do perímetro urbano, considerada relativamente alta para o país. Tal cidade foi escolhida para a pesquisa de campo porque, devido às suas configurações populacionais e distribuição geográfica, apresenta interessantes características de coesão e homogeneidade da população a ser estudada que, de acordo com Bardin (2004), garante a qualidade da amostragem.

A amostra foi composta por 38 discentes: 19 do sexo biológico feminino e 19 do sexo biológico masculino, todos cursando o último semestre do Ensino Médio regular, de maneira a captar, de forma mais ampla possível, a condição de formação discente obtida no final do percurso do ensino médio. As entrevistas foram executadas mediante aprovação do Comitê de Ética em Pesquisa da Universidade Estadual de Mato Grosso 
do Sul (UEMS), com parecer registrado na Plataforma Brasil, do Ministério da Saúde, sob o número 57596716.4.0000.8030.

Após assinatura de termos de consentimento, por parte dos responsáveis maiores de idade, e termos de assentimento, por parte de alunas e alunos menores de idade, estes se submeteram às entrevistas semiestruturadas (MANZINI, 2012), iniciadas com perguntas diretivas, a partir das quais, em função da evolução da entrevista, puderam ser complementadas por outras perguntas elaboradas ocasionalmente, de maneira a se obter dados mais aprofundados.

Bloco A: - O que você pensa sobre igualdade de direitos entre homem e mulher? - Por que pensa assim? Bloco B: - O que você pensa sobre o relacionamento entre pessoas do mesmo sexo? - Por que pensa assim? Bloco C: - O que pensa sobre as pessoas que se sentem, agem e se apresentam de forma diferente em relação ao seu sexo biológico? - Por que pensa assim? (CAROLLI, 2017, p. 193).

Foi possível identificar, ainda durante a execução das entrevistas, o surgimento de uma coleção de "enunciados" (FOUCAULT, 2008) discriminatórios consistentes, atingindo um "ponto de redundância" (ALVES-MAZZOTI; GEWANDSZNAJDER, 2001), a partir do qual a repetição dos enunciados, com o cessar do aparecimento de novos dados, apontou que o objetivo de obtenção de informações sobre os discursos discriminatórios havia sido atingido. Os enunciados foram elencados e receberam, para organização, um código formado pelo número da entrevista, gênero do participante, número da ocorrência na entrevista e uma letra final para designar enunciado explícito ou implícito. (CAROLLI, 2017).

$\mathrm{Na}$ segunda fase, passou-se a investigar o pertencimento dos enunciados elencados a diferentes "Formações discursivas" (FOUCAULT, 2008) originais, que deveriam ser identificadas antes de se dar prosseguimento à análise: "[...] Chamaremos de discurso um conjunto de enunciados, na medida em que se apoiem na mesma formação discursiva; [...] constituído de um número limitado de enunciados para os quais podemos definir um conjunto de condições de existência. [...]". (FOUCAULT, 2008, p. 132-133, grifo nosso).

Na terceira fase da pesquisa foi utilizado o método "arqueológico" (FOUCAULT, 2008), mediante o qual foram buscadas as fundamentações históricas que apoiam na atualidade os enunciados discriminatórios detectados nos discursos, considerados em seus contextos originais, esses últimos, relativos à episteme da época da materialização dos enunciados discriminatórios fundantes. Essa etapa buscou, também, definir as "condições de produção" (FOUCAULT, 2008) dos discursos.

$\mathrm{Na}$ quarta fase desta investigação foram feitas comparações dos significados de palavras-chave, selecionadas a partir dos enunciados analisados, comparando o seu significado, em seu contexto original, com o significado que poderiam ter contemporaneamente, segundo uma epistemologia atualizada, de acordo com o fenômeno do "Rastro" (DERRIDA, 1973), o qual explica as mudanças de significados de uma palavra em função do tempo e da episteme presente nos momentos de enunciação.

Na quinta fase da pesquisa foram investigados os discursos com base no conceito filosófico do Logocentrismo, trazido por Derrida (1973), para uma discussão sobre a composição ideológica dos discursos discriminatórios. Nesse momento, incluiu-se, 
também, o emprego da Lógica Formal ${ }^{5}$ aristotélica ${ }^{6}$ na análise de como se relacionam os conceitos presentes nos discursos na sua produção da significação, atualmente, especialmente quanto à discriminação relativa à Gênero e Sexualidade. Segundo Chauí (2000, p. 231), a Lógica Formal “[...] é o instrumento do pensamento para pensar corretamente e verificar a correção do que está sendo pensado [...]".

Na sexta fase da investigação, utilizou-se da Análise de Conteúdo de Bardin (2004), na variante proposta por André (1983), denominada "Análise de prosa", para identificar e elencar categorias de discriminações expressas nas proposições elencadas, de maneira que foi possível obter alguns dados estatísticos sobre a incidência de tipos de discriminações.

A sétima, e última, fase da análise interpretou as proposições elencadas, e as formações discursivas evidenciadas, segundo a ótica da Genealogia do Poder, de Foucault $(1999,2006)$, conceito usado para analisar as intenções veiculadas pelos discursos como veículos que articulam Poder e Saber para a moldagem de indivíduos (FOUCAULT, 2006).

\section{Resultados e discussões}

As proposições discriminatórias obtidas mediante as análises das transcrições das entrevistas foram organizadas em conjuntos, correspondentes às principais formações discursivas detectadas: formação discursiva da discriminação do Gênero feminino, formação discursiva da discriminação das Sexualidades não normativas, especialmente da homossexualidade, formação discursiva da discriminação quanto à Travestilidade ${ }^{7}$, como descrita por Patrício (2002), que também associou a Transexualidade ${ }^{8}$, como descrita por Cauldwell (2006).

\section{Das formações discursivas, características e estatísticas em destaque}

Além dos diagnósticos quanto às formações discursivas, também foi possível produzir algumas estatísticas sobre esses discursos discriminatórios, que permitiram um vislumbre da dimensão desse problema educacional.

Nas três formações discursivas principais detectadas, pôde-se constatar que, nas origens dos discursos discriminatórios, encontram-se enunciados fundantes presentes em textos bíblicos.

\footnotetext{
${ }^{5}$ Lógica: palavra de origem grega, é a parte da filosofia que trata das formas do pensamento em geral (dedução, indução, hipótese, inferência, etc.) e das operações intelectuais que visam determinar o que é verdadeiro ou não em uma proposição. A palavra "Lógica" se relaciona com o logos, razão, palavra ou discurso e é o instrumento do pensamento para um raciocínio correto, que leva à conclusão verdadeira sobre um determinado objeto analisado. A lógica formal se desenvolveu especialmente com o pensamento grego antigo, no qual se destaca o trabalho do filósofo Aristóteles.

${ }^{6}$ Aristóteles (384 a. C. a 322 a. C.) foi um filósofo grego. Aluno de Platão e professor de Alexandre, o Grande. Juntamente com Platão e Sócrates, ele é reconhecido como um dos fundadores da Filosofia no mundo ocidental.

7Travestilidade é um conceito que, inicialmente, descreve a 'criação do feminino' por um indivíduo de sexo masculino, mediante a construção da apresentação do gênero feminino com comportamentos e uso de cuidados corporais, adornos e vestimentas entendidas por uma cultura e época como de hábitos próprios desse gênero. A formação discursiva detectada na pesquisa apresentada neste artigo, relativa à discriminação da travestilidade, por ter origem em leituras literais de textos bíblicos, fixa-se na apresentação do gênero, não a distinguindo do fenômeno da transexualidade.

${ }^{8} \mathrm{O}$ conceito, entendido em um primeiro momento, como uma psicopatia, sofreu ressignificação no contexto científico contemporâneo. Assim, transexualidade, deve ser entendida como a condição de necessidade de um indivíduo de adaptação a uma configuração corpórea de sexo biológico que não seja o seu sexo de nascimento. Na pesquisa apresentada neste artigo apurou-se que, nos discursos correntes entre discentes do Ensino Médio, o preconceito que discrimina a transexualidade, em geral, não a distingue da travestilidade.
} 
A partir da análise de cada proposição elencada,com a definição do pertencimento destas a cada formação discursiva, segundo suas condições ou "regras de aparecimento" (FOUCAULT, 2008), apurou-se que as discriminações quanto à Sexualidade e Gênero (quanto à mulher, à homossexualidade, à travestilidade e à transexualidade), estavam presentes no discurso de 21 discentes, que correspondem a 55,2\% do total de participantes. Dentre todas as entrevistadas e de todos os entrevistados, oito participantes da pesquisa, correspondentes a $21 \%$ do total, apresentaram proposições discriminatórias quanto ao gênero feminino em suas falas. Do total de entrevistados, 16 participantes, correspondentes a $42 \%$, verbalizaram alguma forma de discriminação quanto à homossexualidade, dentre os quais, nove participantes, correspondentes a $23,7 \%$ do total de entrevistados, responderam a partir de textos bíblicos, direta ou indiretamente, para embasar seus discursos discriminatórios. Os dados estatísticos quanto ao discurso discriminatório da homossexualidade confirmaram claramente que a exclusão da sexualidade não normativa tem base nas escrituras da religião judaicocristã, como descreve Borrillo (2010).

As discriminações quanto à travestilidade e transexualidade foram elencadas em conjunto, pelo fato de entrevistadas e entrevistados, em geral, não fazerem distinção entre esses conceitos. Constataram-se enunciados discriminatórios da travestilidade em 13 entrevistas, correspondentes a $34,2 \%$ do total de participantes, entre as quais, nove entrevistas correspondentes a $23,7 \%$ do total, representadas por cinco mulheres e quatro homens, que também expressaram enunciados discriminatórios citados a partir de textos bíblicos.

Em todos os casos nos quais foi possível identificar os enunciados fundantes dos discursivos discriminatórios, a Bíblia foi citada diretamente; em outros casos, outras fontes de fundamentação não foram citadas, indicando uma naturalização do discurso, na qual a discriminação é assumida como um estado de coisas natural, que não precisa ser explicado.

Foi possível observar, durante a análise, que indivíduos submetidos à ação de discursos discriminatórios, não raramente, se colocam a serviço do Poder veiculado por esses, ajudando, inclusive, a perpetuar e até a reforçar ideologias mediante a reprodução e o reforço dos discursos recebidos, como um "[...] efeito manifestado e às vezes reconduzido pela posição dos que são dominados [...] (FOUCAULT, 2006, p. 29).

A partir da identificação dos principais discursos discriminatórios, passou-se a investigar suas origens e os encadeamentos lógicos de seus enunciados, examinados do ponto de vista histórico e científico, para se verificar a validade de suas premissas sustentadoras, como apresentamos mais à frente.

\section{Da discriminação do gênero feminino}

Sobre a discriminação do gênero feminino a partir de textos religiosos, encontraram-se os enunciados fundantes do discurso, presentes no Primeiro Testamento bíblico. São as passagens de Gênesis 2:18 e 3:16, respectivamente:

a. "Iahweh Deus disse: Não é bom que o homem esteja só. Vou fazer uma auxiliar que Ihe corresponda" (BÍBLIA, 2002, p. 36);

b. "À mulher Ele disse: Multiplicarei as dores das tuas gravidezes, teu desejo te impelirá ao teu marido, ele te dominará" (BÍBLIA, 2002, p. 38). 
As duas passagens, destacadas do Primeiro Testamento, ou seja, da Bíblia judaica, que é uma base importante para toda a cultura ocidental, colocam o gênero feminino, de maneira explícita, em uma posição subalterna ao gênero masculino, definindo que a mulher seja uma 'auxiliar' à qual o homem 'dominará'. Esses enunciados fundantes do discurso discriminatório que submete o gênero feminino na cultura ocidental, encontrados no texto do livro Levítico, segundo a tradição, datariam de 1.200 anos antes de Cristo, ou seja, datariam de 3.200 anos atrás e teriam sido elaborados no final da Idade do Bronze. A historiografia, entretanto, aponta que alguns desses textos, provavelmente, teriam sido reeditados no século sétimo antes de Cristo, durante o cativeiro de Israel na Babilônia (MONTALVÃO, 2009).

Verificou-se que o princípio de submissão do gênero feminino é reproduzido nos discursos do Segundo Testamento (CAROLLI, 2017), por influência cultural judaica sobre a religião cristã, mediante a herança dessa formação discursiva. Tendo em vista a incidência estatística observada, infere-se que este seja um importante motivo para que tal discurso discriminatório persista até hoje na cultura ocidental.

\section{Da discriminação da homossexualidade}

O discurso discriminatório sobre a homossexualidade teve o enunciado fundante localizado no texto bíblico de Levítico 18:22, no qual consta: "Não se deitarás com um homem como se deita com uma mulher. É uma abominação" (BÍBLIA, 2002, p. 187). A análise das formações discursivas discriminatórias da homossexualidade, a partir de textos bíblicos relacionados, evidenciou que, a partir desse enunciado original, foram criados os discursos discriminatórios relativos a esse tema (CAROLLI, 2017), mesmo os presentes no Segundo Testamento, em "formações discursivas" (FOUCAULT, 2008) correspondentes que, aparentemente, confirmariam a proibição original, trazendo novos dados, mas que, na realidade, apenas representam o "efeito" (FOUCAULT, 2006), de reprodução discursiva, do princípio indicado pelo enunciado fundante, existente no Primeiro Testamento.

Quanto a essa proibição original, a contribuição de Montalvão (2009) confirma que tal versículo compõe um quadro de proibições de práticas religiosas estrangeiras que Israel queria evitar à época da produção do livro Levítico, relacionadas a uma prática de sexo cultual, oferecida a deuses estrangeiros a Israel. Assim, a adoção dessa prescrição como norma de conduta para indivíduos religiosos judaico-cristãos, na contemporaneidade, conflitaria com o fato de este tipo de sexo cultual não mais existir. Por outro ângulo, a desobrigação dos cristãos com relação às 613 prescrições da lei judaica, institucionalizada no livro Atos dos Apóstolos, no capítulo 15 (CAROLLI, 2017), no século primeiro, indicaria uma leitura seletiva e contraditória, por parte de quem ainda defende essa proibição, posto que a antiga lei judaica, já abandonada por religiosos, por exemplo, autorizava, até mesmo, a escravização de seres humanos, como se lê em Levítico, 25:44-46, e não mais admitida entre cristãos e judeus. A evidenciação de contradições como estas, existentes dentro do próprio discurso religioso, demonstra a invalidade atual de tais prescrições e é um dos movimentos característicos da Desconstrução. 


\section{Da discriminação da travestilidade}

Esta última modalidade de discriminação funde travestilidade, transexualidade e homossexualidade pois, entrevistadas e entrevistados demonstraram não ter clareza quanto à diferença entre estes conceitos. Este tipo de discriminação também não tem um único enunciado fundante no discurso religioso judaico-cristão, pois se relaciona ao enunciado relativo a relações homossexuais, contido no livro Levítico, 18:22, e também consta, literalmente, no Livro do Deuteronômio, 22:5: "A mulher não deverá usar um artigo masculino, e nem o homem se vestirá com roupas de mulher; pois quem assim age é abominável a lahweh teu Deus" (BÍBLIA, 2002, p. 284).

Apesar de, à primeira vista, a proposição aparentar apresentar uma simples e direta proibição com relação à travestilidade e à transexualidade, ou ainda, a todas as identidades de gênero não normativas, esse versículo, descontextualizado, não pode ser entendido simplesmente como condenação às categorias sociais hoje relacionadas, por comunidades religiosas, a esse texto, porque esse aparece originalmente compondo um quadro de condenação a práticas cultuais estrangeiras a Israel.

As passagens que compõem o contexto de proibição das práticas religiosas estrangeiras no Primeiro Testamento são: Levítico, 18:22 (BÍBLIA, 2002-187), como também, a passagem do Livro do Deuteronômio, 23:18-19 (BÍBLIA, 2002, p. 286); Primeiro Livro de Reis 14:24 (BÍBLIA, 2002, p. 492), 15:12 (BÍBLIA, 2002, p. 493) e 22:46 (BÍBLIA, 2002, p. 506), além do Segundo Livro de Reis 23:7 (BÍBLIA, 2002, p. 540). No contexto de todas essas passagens, o discurso tem a conotação da condenação da prostituição masculina relacionada a práticas cultuais e à adoração de deuses estranhos aos rituais judaicos, declaradas 'abominação' a Deus, associadas, nessa ocasião, à travestilidade, conforme o enunciado fundante de Levítico, 18:22, que proibiria relações homossexuais, já analisado anteriormente. A 'abominação' relativa a essas práticas tinha por objetivo manter a pureza cultual no meio israelita, segundo Montalvão (2009). Assim, as proibições de relações homossexuais e da travestilidade existiriam em função da pureza cultural israelita e não propriamente em função do tipo de relação sexual praticada. De acordo com Montalvão (2009, p. 17): "Sem estes sete versículos, se torna impossível e inviável uma leitura aprofundada sobre a perspectiva hebraica e cananéia com respeito a homossexualidade."

\section{Da leitura descontextualizada}

Como demonstrado por Saussure (2013), significados e significantes sempre serão provisórios, mudando em função do tempo. Em função dessa instabilidade da linguagem, Derrida (1973) desenvolveu o conceito do "Rastro" para explicar a origem da significação. O autor demonstra que o aparecimento da significação é nada mais do que um efeito contextual da linguagem, que descarta qualquer ligação positiva entre significante, significado e a coisa significada, ligação esta que seria, para a tradição, uma "origem" para a significação:

[...] O rastro não é somente a desaparição da origem, ele quer dizer aqui - no discurso que proferimos e segundo o percurso que seguimos - que a origem não desapareceu sequer, que ela jamais foi retroconstituída a não ser por uma não-origem, o rastro, que se torna, assim, a origem da origem. [...]. (DERRIDA, 1973, p. 75). 
O autor define que "[...] O rastro é [...] não mais uma significação transparente que uma energia opaca e nenhum conceito metafísico pode descrevê-lo. [...]" (DERRIDA, 1973, p. 79-80). O Rastro, assim, é configurado por Derrida como um fenômeno linguístico, material e histórico, ligado à convenção temporal, que é a própria linguagem. Derrida assim também desfaz a pretensão de ligação da significação à metafísica do Logocentrismo.

O emprego desse conceito permitiu esclarecer que não existe leitura literal que possa trazer de volta o significado original de um texto; tal tipo de leitura, com a simples dependência de significados e significantes, que são instáveis, é uma leitura falsa, no sentido de ser uma ilusão para quem lê, por esta captar apenas uma aparência, pois as configurações da linguagem são sempre dependentes do contexto de cultura e época, que geram o efeito do aparecimento da significação. Dessa forma, um texto não pode significar corretamente, caso esteja destacado do contexto no qual foi produzido; uma leitura de época diferente à época do leitor não pode fazer efeito de significação corretamente se o leitor não conhecer amplamente o contexto da produção do texto que esteja lendo.

Em função dessa leitura contextual, foram analisadas as significações de algumas palavras-chave envolvidas nos discursos discriminatórios da Sexualidade e Gênero, como pecado, natural, iniquidade e homossexual, cujos efeitos de significação são determinantes para a sustentação dos discursos em foco.

Explicando as referências anteriores, temos que a palavra pecado, tomada pelo significado tradicional de 'erro', muda sua significação na cultura judaico-cristã e no Ocidente, a cada época; a significação da palavra natural é atualizada constantemente por diferentes campos da Ciência, quando envolve discussões sobre práticas sexuais (CAROLLI, 2016). A palavra iniquidade, de especial significado à religião judaico-cristã, remete a uma discussão relativa à luta contra condições desiguais entre pessoas; por fim, a desconstrução da significação da palavra homossexual, mostra que essa assumiu a significação de uma categoria social, ou uma "espécie" (FOUCAULT, 1999, p. 42-43) que, na verdade, é fictícia, por ser apenas um efeito construído pela linguagem, a partir de interpretações preconceituosas das ciências no século 19 (FOUCAULT, 1999), que utilizavam pressuposições logocêntricas. Assim, a própria Ciência, valendo-se de pressupostos logocêntricos, também ofereceu uma base para que se gerasse a iniquidade do tratamento depreciativo para esse nominado grupo social, no século 20. Hoje, ressignificando este discurso, estudos realizados por diferentes campos científicos, apontam a homossexualidade como uma característica regular da espécie humana, como também afirma Borrillo (2010).

Essa atualização constante de conceitos, associados à significação das palavras, promovida pela Ciência, também é um movimento da Desconstrução descrita por Derrida (1973).

Apesar dos recentes avanços científicos e sociais, leituras literais descontextualizadas de escrituras religiosas judaico-cristãs figuram, ainda hoje, como principais bases para sustentação dos discursos discriminatórios de Gênero e Sexualidade, gerando desdobramentos como a elaboração de explicações forçadas, desprovidas de lógica, para conceitos que não correspondem mais à realidade social atual e, tampouco, ao que é definido pela Ciência atual.

Exemplos dessas explicações forçadas são descritos a seguir. 


\section{Da lógica falsa envolvendo preconceitos}

A lógica é o instrumento necessário a um raciocínio correto; é necessária para que seja possível a obtenção de uma conclusão verdadeira sobre um determinado assunto analisado. Segundo Chauí (2000, p. 48): "A lógica não é uma ciência, mas o instrumento para a ciência [...]"

A lógica formal se desenvolveu inicialmente no pensamento grego antigo, no qual se destaca o trabalho de Aristóteles, por isso também é chamada 'lógica aristotélica'.

A verificação do uso correto da lógica se apresentou como um instrumento poderoso para a verificação da validade dos enunciados discriminatórios. Constatouse que a razão tradicional, representada no pensamento ocidental pelo Logos, está presente na base de muitas proposições discriminatórias elencadas neste trabalho e, ainda, constatou-se que essa não responde mais com coerência frente à epistemologia científica contemporânea, dissociando-se, assim, da Ciência. Do ponto de vista da lógica científica, é possível afirmar que: "A lógica do logos, isto é, a lógica tradicional ocidental, choca-se com a racionalidade apresentada pela ciência, pois, pela visão científica da realidade, a verdade não pode mais ser simplesmente anunciada: esta precisa ser demonstrada." (CAROLLI, 2017, p. 30). Assim,

[...] A 'racionalidade' - mas talvez fosse preciso abandonar essa palavra [...] não é mais nascida de um logos e inaugura a destruição, não a demolição mas a de-sedimentação, a desconstrução de todas as significações que brotam da significação de logos. [...] Em especial a significação de verdade. [...]. (DERRIDA, 1973, p. 12-13, grifo nosso).

Derrida (1973) chama a atenção para o fato de que a tendência do pensamento ocidental de colocar a razão tradicional, ou seja, o Logos, como centro de muitos discursos elimina, em muitos casos, a análise e a verificação, por se assumir uma verdade de fundo teológico no apoio a muitas afirmações, como se esta fosse natural, dada desde sempre. Daí a afirmação de que a racionalidade moderna, científica, "[...] não é mais nascida de um logos [...]" (DERRIDA, 1973, p. 12-13).

A afirmação de Derrida pode ser parafraseada para permitir um entendimento mais claro quanto ao pensamento científico contemporâneo: “[...] a racionalidade não é mais nascida de palavras dadas" (CAROLLI, 2017, p. 30). Assim, a racionalidade, do ponto de vista científico, somente pode existir a partir da demonstração dos fenômenos e da coerência dos discursos.

Nesse ponto, aparece um aspecto importante sobre o conceito de Desconstrução que, percebe-se, confunde alguns escritores: ela não representa a 'demolição', mas a 'de-sedimentação' dos discursos logocêntricos. Não se trata, portanto, de uma simples substituição de discursos, mas de um processo que, mediante análise, ressignifica conceitos, partindo de discursos preexistentes. Dessa maneira, nem mesmo a justa causa dos movimentos sociais seria motivo isolado para a substituição de discursos tradicionais, por outros, mais atuais, na busca de justiça social. Diferentemente disso, as novas significações são o resultado de exames em profundidade que 'de-sedimentam' construções sócio-históricas enraizadas há muito na cultura, vindo ao encontro de demandas sociais, que representam a realidade, e ganham mais legitimidade quando demonstradas como verdadeiras. Por isso, o significado da palavra 'Desconstrução' se 
aproxima do significado de 'Análise': "[...] está muito mais perto do significado original da palavra análise, que, etimologicamente, significa desfazer. Portanto, ao se eleger a desconstrução como procedimento metodológico, está se indicando um modo de questionar ou de analisar [...]" (LOURO, 2001, p. 548).

De fato, a presente pesquisa permitiu verificar com clareza que, neste caso, o Logos representado pelas ideias tradicionais, de origem religiosa, apresenta ausência de fundamentação científica, ou seja, fundamentação verificada para suas alegações. Ainda, em muitos momentos, o discurso com base logocêntrica apresenta lógica falha e até inexistente em suas proposições, quando veicula conceitos que embasam discriminações relativas à Sexualidade e Gênero, vindo ao encontro da necessidade de se eliminar esse tipo de iniquidade em nossa sociedade, evidenciando que esta é uma reivindicação justa de movimentos sociais.

Outra característica logocêntrica apontada por Derrida (1973), presente nos discursos discriminatórios, é a existência de binarismos como homem-mulher e certo-errado, que participam de raciocínios com lógica demonstrada como inválida, com inferências forçadas, para se enquadrarem em conclusões preestabelecidas por "palavras dadas" ou por uma visão "nascida de um logos" (DERRIDA, 1973, p. 12-13).

A necessidade da tradição do pensamento ocidental de enquadrar todas as escolhas
entre um pólo 'certo' e outro 'errado', entre uma extremidade superior e outra
inferior, desconsiderando quaisquer outras possibilidades, leva a se desenvolverem
raciocínios sem lógica que chegam a muitas conclusões inválidas. Dessa maneira,
muitas discriminações quanto a sexualidade, gênero, raça, etnia e classe social
"fundamentam-se" meramente em pares de categorias apresentadas como opostas,
naturalizadas e não questionadas, que não passam de meros efeitos de linguagem.
(CAROLLI, 2017, p. 132).

Um dos movimentos da Desconstrução é expor a artificialidade de certos binarismos, de maneira que seja percebida a invalidade dos raciocínios discriminatórios, baseados em efeitos de linguagem, que provêm de hierarquização de categorias, arbitrariamente convencionadas como opostas.

Se um par de categorias opostas tratar-se de um artifício, ou seja, de mera construção de linguagem que não possui fundamentação na realidade, desmancham-se as noções de cada definição à medida que se demonstra como foi realizada essa construção. Os discursos binaristas relativos à sexualidade serão então ressignificados ou, simplesmente, não terão mais sentido em existir, se for o caso, desaparecendo, por exemplo, o sentido da existência de categorias de pessoas colocadas à margem da sociedade devido a esse critério de classificação. (CAROLLI, 2017, p. 78).

Sintomaticamente, em 11 entrevistas, correspondentes a 28,9\% do total, discentes citaram os termos binários 'certo' ou 'errado', associando, em seis entrevistas, esse par binário, diretamente, às escrituras da religião judaico-cristã, correspondendo à significativa parcela de $15,7 \%$ do total de entrevistas, tornando, mais uma vez, evidente o logocentrismo do discurso, como no exemplo:

Inquérito - "Então você disse que não concorda com o ato que eles fazem. Tem um motivo para não concordar. Existe uma base. Não e isso? Você poderia descrever essa base, motivo? Informação verbal - Ah... Motivo e que eu não acho certo. Porque eu sou evangélica. Então, eu sou conhecedora da palavra. Então, Deus criou Adão e Eva. Deus não criou Eva - Eva e Adão - Adão. Não! Deus criou Adão e Eva. E assim a criação continuou, de geração para geração." [15f]. (CAROLLI, 2017, p. 132, grifo nosso). 
Composições binaristas, de base logocêntrica, mostraram-se comuns, como também acontece na sequência "[informação verbal] [...] Criou homem e a mulher. Não criou homem e o homem. [...] [10m]". (CAROLLI, 2017, p. 128, grifo nosso).

O "[...] encadeamento dos juízos constitui o raciocínio e este se exprime logicamente através da conexão de proposições; essa conexão chama-se silogismo. [...]". (CHAUÍ, 2000, p. 232). Com o emprego da Lógica Formal, verifica-se que a proposição analisada é derivada de um silogismo falso, porque a segunda premissa é simplesmente um enunciado elaborado para criar um par para oposição arbitrária à primeira premissa; trata-se de nada mais que um enunciado criado com base em um binarismo de oposição artificial entre as categorias da heterossexualidade e da homossexualidade, que também constituem um par binário, que traz um conceito previamente definido, de exclusão e base logocêntrica. A materialização completa desse silogismo falso seria: "Deus criou homem e a mulher. Não criou homem e o homem. Logo, não pode haver relações entre homem e homem" (CAROLLI, 2017, p. 128). A conclusão do pretenso silogismo é, nesse caso, flagrantemente falsa, visto que essa aparece apenas sob a forma de "[...] um enunciado livre de qualquer relação de causa lógica, ou seja, nesse caso, é apenas a repetição de uma pressuposição provinda de um discurso adquirido" (CAROLLI, 2017, p. 129).

Essa mesma construção silogística falsa aparece em seis entrevistas (7f; 10m; $11 \mathrm{f} ; 15 \mathrm{f} ; 16 \mathrm{~m} ; 19 \mathrm{~m})$, correspondentes a $15,7 \%$ do total de entrevistados. Essas seis entrevistas citam a religião judaico-cristã como fonte de seu discurso discriminatório, indicando que é comum, nesse meio religioso, a aceitação desse tipo de proposição sem que esteja presente a lógica.

A presença de significativa parcela de participantes da pesquisa, que usaram tais inferências falsas, similares às apresentadas, que são comumente tomadas como base para se rechaçar relações sexuais e afetivas entre pessoas do mesmo sexo, coagindo pessoas à subordinação a uma norma social, mediante discriminação, indica a necessidade de uma reflexão sobre a sua formação escolar relativa a competências e habilidades usadas para a interpretação de textos.

Conceitos provindos do logocentrismo são, dessa forma, pretensamente legitimados pelo próprio discurso, do qual, as afirmações verbais seguintes, mais uma vez, literalmente associadas ao Logos, por duas alunas participantes da pesquisa, são especialmente representativas dessa "ideologia" (OLIVA, 2014) discriminatória e de sua "formação discursiva" (FOUCAULT, 2008).

"[Informação verbal] [...] Desde o verbo [Logos], desde o começo, já foi feito homem e mulher [...] [15f]" (CAROLLI, 2017, p. 130, grifo nosso).

"[Informação verbal] [...] Deus faz as coisas perfeitas. Então ninguém tem que ficar mudando, entendeu? Nem precisa ter ninguém para ficar mudando as lógicas [Logos] que Deus colocou [...] [11f]." (CAROLLI, 2017, p. 164, grifo nosso).

Por fim, apesar de ideias preconcebidas quanto à Sexualidade e Gênero serem comuns nos discursos estudados, há alunas e alunos que, observando a realidade, em uma ação que denota reflexão, conseguem, em certa medida, desconstruir e superar os preconceitos, como apurado em algumas declarações: 
[...] Nas 38 (trinta e oito) entrevistas empreendidas, foram documentadas 17 (dezessete) ocorrências questionadoras do Poder da religião em 11 (onze) depoimentos [...], ou seja, em $31,8 \%$ do universo pesquisado, que mostram que as entrevistadas e entrevistados, em certos momentos, fazem a Desconstrução de discursos discriminatórios. (CAROLLI, 2017, p. 132).

Apesar da alta incidência de discursos discriminatórios, observa-se que parcela significativa da população discente do Ensino Médio, na realidade observada, está aberta ao questionamento da tradição quando essa é confrontada com a realidade contemporânea e se mostra com conceitos desatualizados.

\section{Considerações finais}

As atuais discriminações de Sexualidade e Gênero estão alicerçadas em pressupostos provindos do discurso inicial religioso judaico, da Idade do Bronze, que passou do Judaísmo ao Cristianismo, reforçado pelo discurso logocêntrico, na Idade Média. Contudo, muitos dos tais conceitos somente começaram a ser questionados a partir da segunda metade do século 20, mediante um processo de Desconstrução, ou seja, um processo de reflexão e ressignificação de diversos discursos, pela sociedade moderna, em função do desenvolvimento social e científico.

Nesta pesquisa, apontamos a necessidade de análise e ressignificação de toda a cadeia silogística discursiva, a partir dos momentos históricos nos quais se verifica a fundação de discursos que, contemporaneamente, se apresentam sem base científica. Assim, perdem sustentação discursos discriminatórios atuais pela demonstração da nulidade de suas fundamentações e pela exposição de suas próprias contradições.

Em resposta ao problema de pesquisa a que se direcionou este trabalho:

\footnotetext{
"Os discursos discriminatórios sobre a diversidade de expressão da sexualidade e identidade de gênero se sustentam?", conclui-se que não, frente à epistemologia científica contemporânea, e conclui-se, conjuntamente, que a Desconstrução se mostra como um caminho viável a ser percorrido para se demonstrar essa afirmação. (CAROLLI, 2017, p. 182).
}

Em função dos dados e resultados obtidos conclui-se que, caso alunas e alunos se apropriassem devidamente da habilidade matemática do emprego da lógica formal e habilidades interpretativas da linguagem, associadas a conhecimentos científicos, muito provavelmente, não reproduziriam de maneira acrítica pensamentos preconceituosos. Isso indica a necessidade de análise do desenvolvimento do currículo escolar relacionado a esses temas.

Leituras literalistas sempre promovem interpretações simples e, muitas vezes, inválidas. Estas retrocedem no tempo a um momento histórico no qual o conhecimento científico não estava disponível para a interpretação dos conceitos envolvidos nos discursos discriminatórios, trazendo ao tempo presente enunciados com significação descontextualizada da episteme atual, gerando e estimulando ideias discriminatórias.

Entendemos que a demonstração das incongruências dessas construções sóciohistóricas, uma vez entendidas, têm o efeito de promover o abandono desse tipo de raciocínio, que se extingue, por si somente, e não por uma simples disputa política envolvendo "Poder e Saber" (FOUCAULT, 2006). 
Em face desses resultados, conclui-se ainda que seja necessário à Ciência abrir o diálogo com o campo religioso para que seja ensinada e realizada a análise contextual do discurso histórico e a promoção de sua atualizada e correta interpretação contextual, baseada no conhecimento contemporâneo, pois, como demonstrado, a permanência de leituras literalistas das escrituras judaico-cristãs figuram como "permanente possibilidade de retrocessos civilizatórios" (CAROLLI, 2017, p.185).

Não há, na proposta da Desconstrução, uma simples chamada a uma disputa política entre diferentes discursos, mas há uma chamada dialógica e analítica, convidando à Ciência, que não deve promover choques, mas a 'de-sedimentação' de conceitos que sejam errôneos.

Avançamos na desconstrução dos discursos discriminatórios da Sexualidade e Gênero até onde foi possível para uma dissertação de mestrado acadêmico, porém, consideramos exitoso o cumprimento do objetivo de apontamento de um caminho teórico para o tratamento de preconceitos no universo escolar, em qualquer nível, e na sociedade.

Apontamos a Desconstrução como um poderoso processo, que pode auxiliar docentes e estudantes na compreensão da construção sociocultural na qual se sedimentam preconceitos e discriminações, tornando evidentes e compreensíveis os motivos pelos quais se deve abandonar e lutar contra discriminações sociais de toda ordem.

\section{Agradecimentos}

Os autores agradecem à Coordenação de Aperfeiçoamento de Pessoal de Nível Superior (CAPES), agência provedora da bolsa de estudos para o mestrado na Universidade Estadual de Mato Grosso do Sul (UEMS), a qual tornou possível este estudo.

\section{Referências}

ALVES-MAZZOTI, A. J.; GEWANDSZNAJDER, F. O método nas ciências naturais e sociais: pesquisa quantitativa e qualitativa. 2. ed. São Paulo: Pioneira Thomson Learning, 2001.

ALTHUSSER, L. Aparelhos ideológicos de estado: nota sobre os aparelhos ideológicos de estado. 3. ed. Rio de Janeiro: Graal, 1985.

ANDRÉ, M. E. D. A. Texto, contexto e significados: algumas questões na análise de dados qualitativos. Cadernos de Pesquisa, São Paulo, n. 45, p. 66-71, 1983. Disponível em: http:// publicacoes.fcc.org.br/index.php/cp/article/view/1491. Acesso em: 13 out. 2021.

BANDEIRA, C. M. Bullying: autoestima e diferenças de gênero. 2009. Dissertação (Mestrado em Psicologia) - Universidade Federal do Rio Grande do Sul, Porto Alegre, 2009.

BARDIN, L. Análise de conteúdo. 3. ed. Lisboa: Edições 70, 2004.

BÍBLIA. Português. Bíblia de Jerusalém. São Paulo: Paulus, 2002.

BORRILLO, D. Homofobia: história e crítica de um preconceito. Belo Horizonte: Autêntica, 2010.

BRASIL. [Constituição (1988)]. Constituição da República Federativa do Brasil. 35 ed. Brasília: Biblioteca Digital da Câmara dos Deputados, 2012. Disponível em: http://bd.camara.gov.br. Acesso em: 15 out. 2021. 
CAROLLI, A. L. Desconstrução de discursos discriminatórios sobre a diversidade de expressão da sexualidade e da identidade de gênero expressos entre alunos e alunas do ensino médio. 2017. Dissertação (Mestrado em Educação) - Universidade Estadual de Mato Grosso do Sul, Paranaíba, 2017.

CAROLLI, A. L. O que é natural: um conceito que influencia profundamente os debates sobre identidade de gênero e diversidade da expressão da sexualidade. In: MILITÃO, A. N.; SANTANA, M. S. R. (org.). Intersecções entre pesquisas/pesquisadores iniciantes no campo educacional. São Carlos: Pedro \& João, 2016. p. 247-261.

CAULDWELL, D. O. Psychopathia transexualis. In: STRYKER, S.; WHITTLE, S. (org.). The transgender studies reader. New York: Routledge, 2006. p. 40-44.

CHAUI, M. Convite à filosofia. São Paulo: Ática, 2000.

DERRIDA, J. Gramatologia. São Paulo: Perspectiva, 1973.

FOUCAULT, M. A arqueologia do saber. 7. ed. Rio de Janeiro: Forense Universitária, 2008.

FOUCAULT, M. História da sexualidade I: a vontade de saber. 13. ed. Rio de Janeiro: Graal, 1999.

FOUCAULT, M. Vigiar e punir: nascimento da prisão. Petrópolis: Vozes, 2006.

GRUPO GAY DA BAHIA. Assassinato de homossexuais (LGBT) no Brasil: relatório 2019. Salvador: Grupo Gay da Bahia, 2019. Disponível em: https://homofobiamata.wordpress.com/estatisticas/ relatorios. Acesso em: 12 out. 2020.

IBGE. Conheça cidades e estados do Brasil. Brasília: IBGE, 2017. Disponível em: https://cidades.ibge. gov.br/v4. Acesso em: 11 de dezembro de 2020.

LOURO, G. L. Teoria queer: uma política pós-identitária para a educação. Revista Estudos Feministas, Florianópolis, v. 9, n. 2, p. 541-553, 2001. DOI: https://doi.org/d4jvgr.

MANZINI, E. J. Uso da entrevista em dissertações e teses produzidas em um programa de pósgraduação em educação. Revista Percurso, Maringá, v. 4, n. 2, p. 149-171, 2012. Disponível em: https://periodicos.uem.br/ojs/index.php/Percurso/article/view/49548. Acesso em: 12 out. 2021.

MIRANDA, E. E.; GOMES, E. G.; GUIMARÃES, M. Mapeamento e estimativa da área urbanizada do Brasil com base em imagens orbitais e modelos estatísticos. In: SIMPÓSIO BRASILEIRO DE SENSORIAMENTO REMOTO, 12., 2005, Goiânia. Anais [...]. Disponível em: http://marte.sid.inpe.br/ col/ltid.inpe.br/sbsr/2004/11.12.11.18/doc/3813.pdf. Acesso em: 20 maio 2017.

MONTALVÃO, S. A. A homossexualidade na Bíblia hebraica: um estudo sobre a prostituição sagrada no antigo oriente médio. 2009. Dissertação (Mestrado em Língua Hebraica, Literatura e Cultura Judaica) - Faculdade de Filosofia, Letras e Ciências Humanas, Universidade de São Paulo, São Paulo, 2009. DOI: https://doi.org/g2m2.

OLIVA, T. D. O discurso de ódio contra as minorias sexuais e os limites da liberdade de expressão no Brasil. 2014. Dissertação (Mestrado em Direito) - Faculdade de Direito, Universidade de São Paulo, São Paulo, 2014.

PATRÍCIO, M. C. Travestismo: mobilidade e construção de identidades em Campina Grande. 2002. Dissertação (Mestrado em Antropologia Social) - Universidade Federal de Pernambuco, Recife, 2002.

SAUSSURE, F. Curso de linguística geral. 34. ed. São Paulo: Cultrix, 2013.

SILVA, T. T. Documentos de identidade: uma introdução às teorias do currículo. 2. ed. Belo Horizonte: Autêntica, 1999. 